\title{
The Impact of Combined Steroid-propranolol Therapy on the Involution of Infantile Hemangioma
}

\author{
Mosaad Abdel Hameed Soliman*, Khalid Abdel Aziz Mowafy, Mohamed Adel Abdel Maksoud, \\ Amr Mostafa Elshafey, Nashaat Abdrabo Elsaadany, Reem Mosaad Soliman
}

Department of Vascular Surgery, Mansoura University, Mansoura, Egypt

\section{Email address:}

Soliman_mosaad@hotmail.com (M. A. H. Soliman), khalid_mowaphy@yahoo.com (K. A. A. Mowafy), M_adel_abdelmaksoud@mans.edu.eg (M. A. A. Maksoud), amrelshafie@mans.edu.eg (A. M. Elshafei), nshaatelsaadany@gmail.com (N. A. Elsaadany), reemsoliman13@gmail.com (R. M. Soliman)

${ }^{*}$ Corresponding author

\section{To cite this article:}

Mosaad Abdel Hameed Soliman, Khalid Abdel Aziz Mowafy, Mohamed Adel Abdel Maksoud, Amr Mostafa Elshafey, Nashaat Abdrabo Elsaadany, Reem Mosaad Soliman. The Impact of Combined Steroid-propranolol Therapy on the Involution of Infantile Hemangioma. American Journal of Pediatrics. Vol. 6, No. 4, 2020, pp. 397-407. doi: 10.11648/j.ajp.20200604.13

Received: September 17, 2020; Accepted: October 7, 2020; Published: October 17, 2020

\begin{abstract}
Infantile hemangioma (IH) is the most common benign vascular neoplasm of infancy, occurring in $1.0-2.5 \%$ of white infants, especially girls. Steroids and propranolol are the most widely used drugs as a primary treatment for IH. Although their mechanism of action is not well understood, their beneficial effect is documented. Our purpose was to compare the clinical efficacy of propranolol alone and propranolol combined with steroids on the outcome of IH. A total of 450 children (median age: 9 months; range: 7 days to 3 years) were included in this randomized controlled study, being treated with combined steroid and propranolol (Group A: 230 children) compared to those treated with propranolol plus placebo (Group B: 220 children). The steroid was given as a loading dose of $2-3 \mathrm{mg} / \mathrm{kg} / \mathrm{day}$ and then gradually tapered over 6 months, whereas propranolol was given as an incremental dose starting at $0.16 \mathrm{mg} / \mathrm{kg} /$ day and reaching a maximum of $2 \mathrm{mg} / \mathrm{kg} /$ day maintained for 18 months (duration of therapy). Frequent monitoring of the blood sugar level was mandatory in the first 2 months: electro- and echocardiograms were recorded initially but not repeated. A more rapid involution rate, recognized by color fading and flattening of the lesions, was noted in Group A compared to Group B, with the peak response reached after 10 months of therapy followed by a slower but steady rate of further improvement. No major adverse effects were observed in Group A with regard to hypoglycemia or hypotension. On the other hand, ten cases of vomiting and diarrhea, one case of fungal infection and twelve cases of somnolence and fatigue were observed in Group B. Steroid induction seems to cover the gap at initiation of therapy where propranolol cannot be given as a full dose, especially in neonates. Steroid combination minimizes the adverse effects of propranolol, namely, hypoglycemia, hypotension and bradycardia. Children treated with a combined regimen showed more effective clearing of lesions, were less likely to require surgery for residual lesions and had minimal adverse effects compared to the single-drug group. In both groups there was a faster clearing rate for the head and neck lesions than elsewhere in the body, which can be explained by the higher blood flow to this region, magnifying the level of medication to these lesions and achieving a better response.
\end{abstract}

Keywords: Infantile Hemangioma, Propranolol, Steroid, Involution

\section{Introduction}

Infantile hemangiomas (IHs) are the most common benign neoplasms in infancy $[1,2]$. The natural history of IHs is characterized by onset within the first weeks of life, followed by a proliferative phase with rapid growth, doubling in size by 6 months of age, and then gradual involution up to 1 year; however, in some cases the proliferative phase may last up to 10 months [3]. About $90 \%$ of IHs spontaneously regress, either partially or completely, within the first 7 years of life [4]. Most IHs are self-limiting but may induce complications in high-risk areas if left untreated. Complications in the periorbital area can lead to amblyopia, displacement of the globe, proptosis and optic nerve compression [5]. Early intervention is indicated in a number of circumstances: visual 
field obstruction, respiratory obstruction, congestive heart failure, severe hemorrhage, serious disfigurement, function-threatening complications and ulceration not responding to local treatment [6]. Meta-analyses of the preferential effects of propranolol and corticosteroids in the treatment of IH reported a lack of well-designed randomized clinical trials [7].

For decades, systemic corticosteroids were considered the mainstay of therapy for hemangiomas. However, their innumerable side effects limit their long-term use [8]. Propranolol has been demonstrated repeatedly as the first-choice drug for $\mathrm{IH}$, with a specific indication for pediatric patients [9]. Propranolol is effective with a reasonable safety profile, but adverse events such as sleep disorders, diarrhea, cold extremities, irritability, hypotension, bradycardia and hypoglycemia have been reported. Although adverse effects are transient and mild, apart from symptomatic hypotension and bradycardia [10], discontinuation of treatment may be required in certain instances [11]. Oral propranolol and topical timolol maleate are more beneficial than placebo in terms of clearance or other resolution measures, or both, without an increase in harm [12].

The present study aimed to provide an overall assessment of the clinical efficacy of propranolol alone versus propranolol combined with corticosteroids on IH with regard to volume reduction, improved overall appearance (e.g. lightening of color and flattening of the surface), improved eye function and also any adverse effects.

\section{Methods}

\subsection{Patients and Methods}

This prospective randomized controlled study was conducted after approval from the Committee of Medical Ethics, Faculty of Medicine, Mansoura University, between January 2010 and December 2015, and included 450 infants (36\% male, 64\% female) with cutaneous IHs who had a median age of 9 months (range: 7 days to 3 years) (Table 1) and were regularly attending vascular clinics at Mansoura province general and private hospitals. Patients were randomized into two groups: one on propranolol plus corticosteroid combined therapy and the other on propranolol plus placebo therapy (Figure 1). Randomization was double-blinded, with patients not knowing which group they were assigned to and assessors not knowing which therapy was given to which patient. The mean size of the $\mathrm{IH}$ was $7 \pm 0.4$ $\mathrm{cm}$ (range: $3-13 \mathrm{~cm}$ ). Ulceration was evident in $12 \%$ of cases at the time of presentation and the majority of them developed by age 4 months. Ulcers were more frequent in larger IHs of mixed type and segmental distribution, located mainly in the lower lip, the neck and the perianal area. Bleeding was associated with ulceration in $4 \%$ of cases, but with no clinical significance. All patients included in the study had no previous history of treatment with any drug or any other therapy.

In both groups, the most frequent indication for treatment with propranolol was potential permanent aesthetic disfigurement for IHs affecting the head and neck region. This was estimated in cases where watchful waiting for spontaneous involution of the IH was rejected by the patients' parents or caregivers or by the treating physicians, especially with lesions exceeding $8 \mathrm{~cm}$ in diameter, followed by function-threatening complications. Two life-threatening lesions were observed in the larynx and painful IHs were reported in seven cases. Patients with the following criteria were excluded: congenital hemangioma, main/extensive deep subcutaneous component, those receiving previous treatment for IH or with hypersensitivity to propranolol, known cardiac disease (heart failure or atrioventricular block), pulmonary disease (asthma or bronchiolitis), diabetes mellitus, visceral hemangioma or PHACE syndrome (see Table 2 and Figure 2).

Measurements of mixed and deep IHs were done with medical grading tape initially and at each follow-up visit in order to determine the area and volume of IH to correlate with the effect and duration of treatment. Even though this method, previously reported by Berk et al. [13], is not the most accurate for the measurement of IHs, we decided to use it because it is a noninvasive procedure and it gives the approximate size of the $\mathrm{IH}$. Photographs of the $\mathrm{IH}$ were taken every 30 days to evaluate the change in color.

Informed consent was obtained from the children's parents or caregivers. After obtaining the signed informed consent of the legal representatives, randomization was carried out by the closed envelope method. Off-label treatment was initiated with oral propranolol in both groups at a dose of 0.16 $\mathrm{mg} / \mathrm{kg} /$ day divided into two doses, gradually increased after 2 weeks to reach a dose of $2 \mathrm{mg} / \mathrm{kg} /$ day and then maintained for 18 months. In Group A, prednisolone was added at a dose of 2 $\mathrm{mg} / \mathrm{kg} /$ day for 3 months, reduced to $1 \mathrm{mg} / \mathrm{kg} /$ day for 3 months and then tapered to $0.5 \mathrm{mg} / \mathrm{kg} /$ day over 2 weeks before stopping completely. For patients with ulcerative lesions, we added topical treatment with mupirocin in the ulcer area to prevent bacterial contamination of the wound and to stimulate healing. An occlusive dressing was applied to prevent bleeding and reduce pain. Patients were checked weekly. Our protocol included a full cardiovascular and respiratory review prior to initiation of therapy, including a complete set of blood tests, a urine dipstick for glucose, electrocardiogram, echocardiogram and abdominal ultrasound. This protocol also endorsed checking blood pressure and heart rate every 30-60 min for the first $4 \mathrm{~h}$ following initiation of therapy and after each dose change, as well as a subsequent periodic assessment of blood pressure, heart rate and blood glucose. The clinical response to propranolol was classified as: excellent (more than $75 \%$ reduction in coloration and hemangioma size, with minimal visible lesions such as telangiectasia at the end of therapy), moderate $(50-75 \%$ reduction), mild (25-49\% reduction), poor (less than $25 \%$ reduction) or no response (slow, with little evidence of diminishing IH) [14]. Evaluation of the response should consider IH measurements, serial photographs and visible clinical effect as subjectively assessed by two different observers blinded to one another's assessment and not those involved in the initiation of 
treatment.

\subsection{Statistical Analysis}

Statistical analysis was performed using Sigma Plot 11.0 (SYSTAT Software Inc., USA). All data are expressed as number, percentage, mean \pm standard deviation (when uniformly distributed) or median and range (when nonuniformly distributed). Student's $t$-test was used for comparisons between the two groups. For three-group comparison, a one-way analysis of variance (ANOVA) was used. A statistical threshold of $p<0.05$ was used as the criterion for statistical significance.

\section{Results}

Patients started treatment at a median age of 9 months, with a range of 7 days to 3 years (Table 1). In both groups, treatment was initiated in the nascent and/or in the proliferative phase. Hemangiomas were distributed in different locations in both groups: in $60 \%$ of patients IHs were predominantly located in the head and neck; the lowest incidence was in the lower extremities (9\%); and multiple lesions were encountered in $6 \%$ of patients (see Table 3 and Figure 3).

Both groups were comparable, with an insignificant statistical difference regarding the age of presentation, age of therapy initiation, duration of therapy and volume of IH. The response to treatment was observed in the first 15 days of treatment, in most cases as a slight decrease in coloration of the IH.

There was a statistically significant overall reduction in the volume of IHs by the end of 6 months in Group A compared to Group B $(p=0.03)$. At the end of the treatment course, an excellent response was observed in $75 \%$ of patients in Group A versus $32 \%$ in Group B ( $p=0.01)$, a moderate response was evident in $10 \%$ of Group A versus $30 \%$ of Group B, a poor response was recorded in $10 \%$ of Group A versus $28 \%$ of Group B and no response was observed in 5\% of Group A versus $10 \%$ of Group B. The majority of excellent responses were located in the head and neck region, whereas the least response was noted in IHs of the feet. In both groups, there was a better response in IHs that were treated at age less than 5 months than those who started treatment beyond that age. Although fading of color and reduction of volume were evident at a median age of 10.7 months in Group A versus 12.2 months in Group B, treatment was continued until the end of the assigned course of 18 months (Figure 4).

With regard to the type of $\mathrm{IH}$, a one-way ANOVA showed that deep and mixed lesions were better responders with a shorter duration than superficial IHs, with a mean of $9.2 \pm 1.9$ versus $10.9 \pm 1.2$ months, respectively $(p=0.04)$. Measurement of deep and mixed lesions at the start of therapy in Group A showed a median volume of $7.3 \mathrm{~cm}^{3}$ that was reduced by $21 \%$ in the first 2 months, by $60 \%$ after 6 months and almost total resolution at 10 months. On the other hand, in Group B, the median volume of $7.1 \mathrm{~cm}^{3}$ at the beginning was reduced by $15 \%$ and $45 \%$ at 2 and 6 months, respectively, with near-total resolution after 12 months $(p=0.02)$.

Our measurements showed that deep and mixed IHs were reduced at a rate of $10 \%$ of their total size every month over a 12-month treatment period. Periocular hemangiomas were observed in 29 patients: 10 had occlusions of the eyes to variable degrees; 6 in Group A and 4 in Group B. There was considerable improvement in both groups but improvement was dramatic in Group A, with rapid regression ending in full eye-opening in all but one lesion that allowed partial opening of the eye after treatment (Figures 5-7). The duration needed to get the eye open was shorter in Group A compared to Group B ( $4 \pm 1.1$ vs. $8 \pm 1.6$ months; $p=0.03)$. A total of 54 patients presented with ulcerated lesions (34 in Group A and 20 in Group B), for which there was an almost equal rate of ulcer healing in both groups ( $4.3 \pm 1.4$ vs. $4.1 \pm 1.6$ months; $p=0.2)$.

In the course of the study, 16 patients (7\%) in Group A presented with mild cushingoid symptoms that were self-limiting and reversible after withdrawal of the steroid and two patients showed upper respiratory tract infection. In Group B, seven patients presented with sleep disorders, five developed diarrhea and one developed an attack of hypotension, tachycardia and pallor. In case of adverse effects, propranolol was stopped for 3 days, followed by halving of the dose, to be gradually increased as tolerated by the patient until therapy was re-established. The adverse effects occurred during the first 2 weeks of treatment, especially when the dosage was increased. However, no discontinuation of therapy due to adverse effects was attempted. Stoppage of treatment was associated with recurrence in six patients (13\%) of Group B but none of Group A, although both groups had the same duration of therapy. All cases of relapse were in females and in lesions with a deep component. None of the children had a change of vaccination timing, especially the live attenuated vaccines.

\section{Discussion}

Infantile hemangioma is the most common vascular tumor of childhood. For a long time corticosteroids were considered the first line of treatment, even if their use was off-label and only limited clinical evidence was available. However, in 2008 a publication by Léauté Labrèze et al. showed the efficacy of propranolol in patients affected by IH [15]. Following this discovery, several publications, including meta-analyses and randomized controlled trials, showed their role in inducing abnormal changes in angiogenesis [16]. Despite the spontaneous regression of $\mathrm{IH}$, usually after 1 year of age, sometimes complications may be severe and waiting for a spontaneous involution may cause irreversible functional and aesthetic damage.

Several mechanisms of action for propranolol have been postulated. Results from combined grayscale and color Doppler ultrasound imaging suggest that propranolol reduces vessel density [17]. Propranolol has a dose-dependent cytotoxic effect on cultured hemangioma endothelial cells via the hypoxia-inducible factor 1 alpha pathway, leading to decreased secretion of vascular endothelial growth factor 
(VEGF) [18]. In vitro, propranolol decreases plasmalemmal expression of GLUT-1 [19], although no study has evaluated this hypothesis to date with respect to IH. Other possible mechanisms of action include inhibition of matrix metalloproteinases, down-regulation of interleukin-6 and modulation of stem-cell differentiation [18].

Corticosteroids have been the mainstream treatment for IHs for many years [20]. However, their effectiveness is limited to the proliferative phase of IH growth and various routes of administration may lead to varying degrees of adverse events, such as growth retardation and infections. There is considerable evidence that beta-blockers are superior to corticosteroids in volume shrinkage and overall improvement in the appearance of cutaneous IHs [21-23] but there is no evidence for a significant difference in improvement of eye function.

In the present study we anticipated that combining propranolol with corticosteroids could minimize the adverse effects and give a better response compared to either drug when used alone, depending on the different mechanisms of action. A significantly higher percentage reduction in the size of the hemangioma was attained in Group A, as well as a shorter average duration of response. Nevertheless, treatment was continued until the predetermined duration of 18 months. Other studies reported an average duration of therapy of 7.2 months, which is lower than the protocol of treatment in our study [24, 25], whereas other reports adjusted the duration for each type of hemangioma and treatment indications [26].

Statistical results showed that the best response was achieved in the first 2 weeks in both groups, with a better response in Group A by the end of the first 6 months. Andersen et al. reported a similar good response when therapy was initiated early, before the age of 6 months [27]. An IH proliferates rapidly in the first 3-6 months after birth, which may explain why the effect of treatment is most evident at this time. On the other hand, a faster response was reported with propranolol used as a monotherapy or in combination with steroids compared to steroids alone [28]. The early initiation of therapy appeared to help prevent longer treatment protocols.

Several studies have reported the use of propranolol at doses ranging from $0.75-1 \mathrm{mg} / \mathrm{kg} /$ day to $2-3 \mathrm{mg} / \mathrm{kg} /$ day [29, 30]. As there is no established dosage in the literature, we considered an initial low dose of $0.16 \mathrm{mg} / \mathrm{kg} /$ day, escalated to $2 \mathrm{mg} / \mathrm{kg} /$ day, to be co-administered with corticosteroid in Group A at a starting dose of $2 \mathrm{mg} / \mathrm{kg} /$ day and then gradually tapered after 3 months when the appropriate dose of propranolol was reached. This combination allowed rapid delivery of the appropriate dose of propranolol within 2 weeks without the considerable side effects of the drug (such as hypoglycemia, bradycardia or hypotension) and avoided dose adjustment or interruption of therapy, especially in the early course of treatment.
Combined therapy with propranolol and corticosteroid has been used in individual cases of IH obstructing the visual axis [30] or the airway [31, 32], followed by steroid withdrawal over a few days or 1 month, in contrast to our study where steroid overlap was kept for 6 months or more to cover the active proliferative phase. Adverse events such as bradycardia and hypotension have been reported as the most common [33], along with inhibited glycogenolysis, the leading cause of hypoglycemia [26]. The dose of propranolol was modified in $16 \%$ of patients due to adverse effects during the first 6 weeks of treatment, especially when the dosage was increased [33]. Other forms of beta-blockers proved to be as effective as propranolol, either timolol locally for cutaneous and ocular IH [34] or acebutolol systemically for subglottic IH [35], but their use was not considered in our study.

Concerning the issue of recurrence, in Group A none of the patients developed lesion recurrence following discontinuation of therapy, compared to Group B where stopping treatment was associated with recurrence in $13 \%$ of patients. This finding could be explained by the more selective effect of steroids on the deeper lesions and emphasizes the value of extending propranolol therapy beyond 1 year, depending on the observations of other studies reporting rebound growth in $15 \%$ of patients after cessation of therapy at 6 months [36], and supports other recommendations that propranolol should be maintained for 1 year or until total involution of the lesion as rebound growth has been noted if treatment is withdrawn too early [37]. The reason for not changing the time of vaccination is ultimately related to a minimal chance of overlap between steroid therapy and live attenuated vaccines. The policy in Egypt is that the BCG vaccine (for tuberculosis) is given soon after birth and the MMR vaccine (for measles, mumps and rubella) at 12-16 months. For children older than 1 year we recommended vaccination before starting steroid therapy, whereas for those already on steroid therapy we advised vaccination as long as the dose is less than $20 \mathrm{mg} /$ day and the weight is less than 10 $\mathrm{kg}$ [38].

\section{Conclusion}

First, steroid induction seems to cover the gap at the initiation of therapy when propranolol cannot be given as a full dose, especially in neonates. Second, steroid combination minimizes the adverse effects of propranolol, namely hypoglycemia, hypotension and bradycardia. Third, children treated with the combined regimen showed more effective clearing of lesions, were less likely to require surgery for residual lesions and had minimal adverse effects compared to the single-drug regimen. Lastly, there was a faster clearing rate for the head and neck lesions than elsewhere in the body, which can be explained by the higher blood flow to this region magnifying the level of medication to these lesions and achieving a better response. 


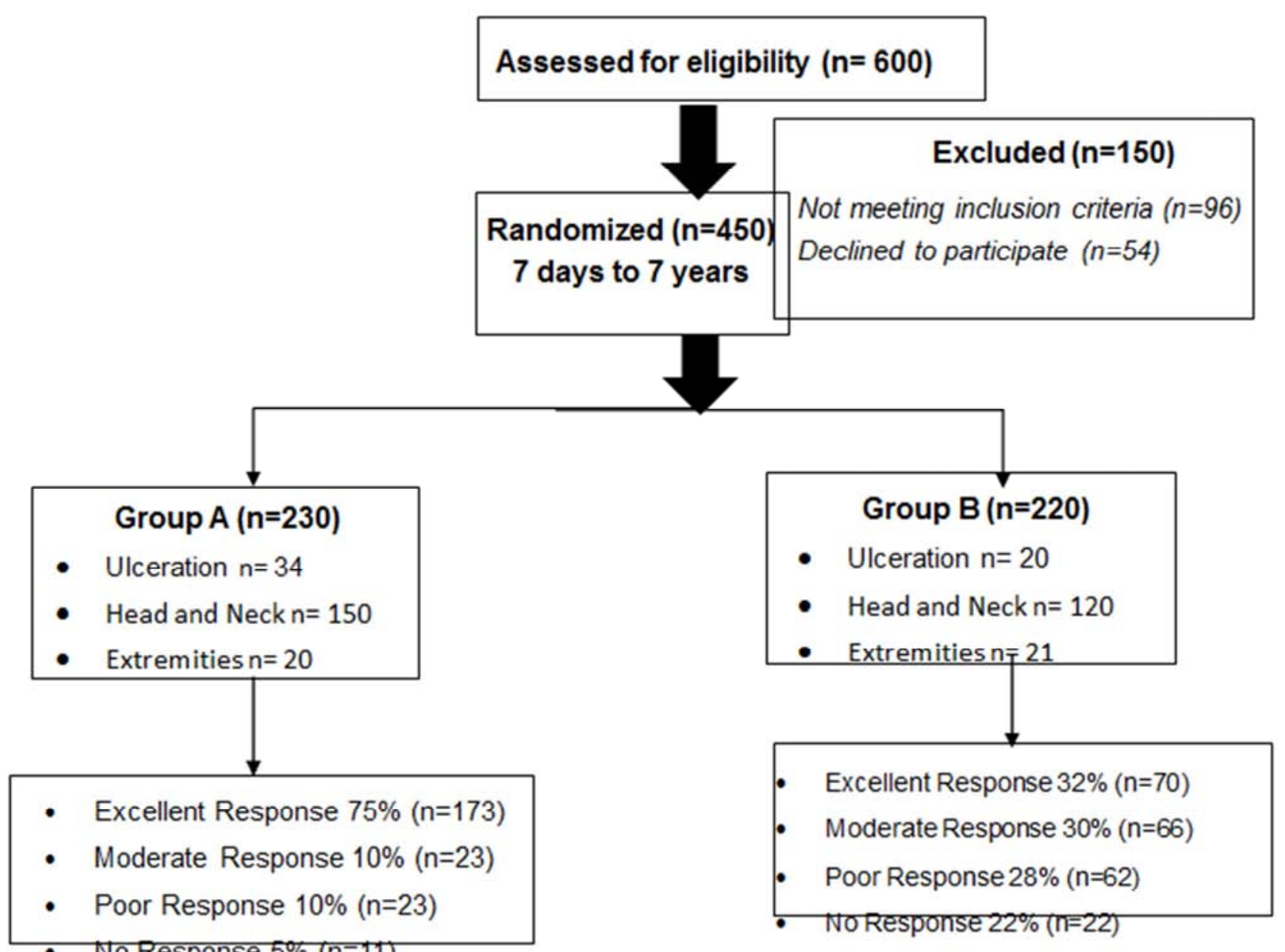

- NoResponse $5 \%(n=11)$

Figure 1. Flowchart outlines the study and outcomes.

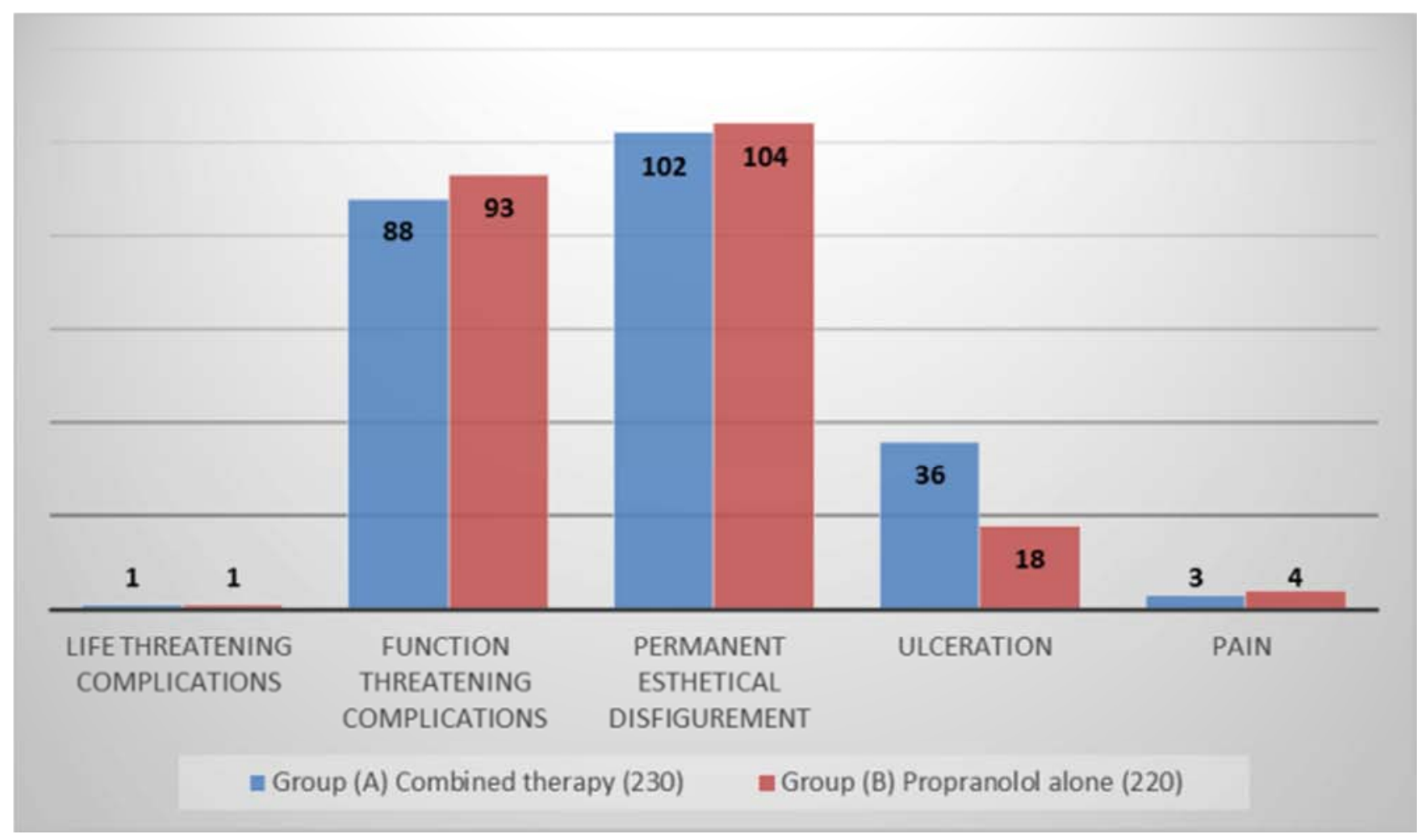

Figure 2. Indications of treatment of infantile hemangiomas included in the study. (no of patients). 


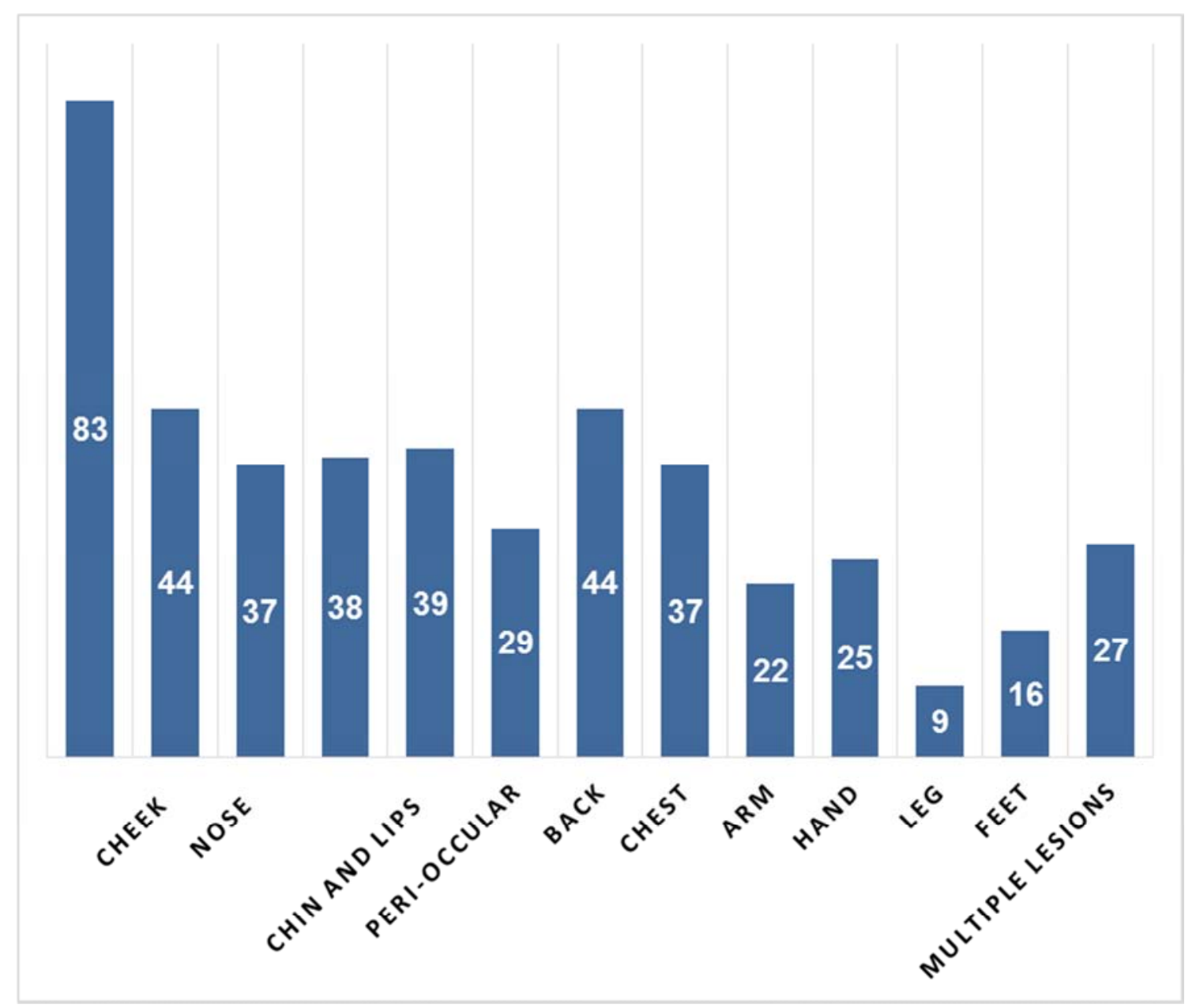

Figure 3. Distribution of Hemangiomas.

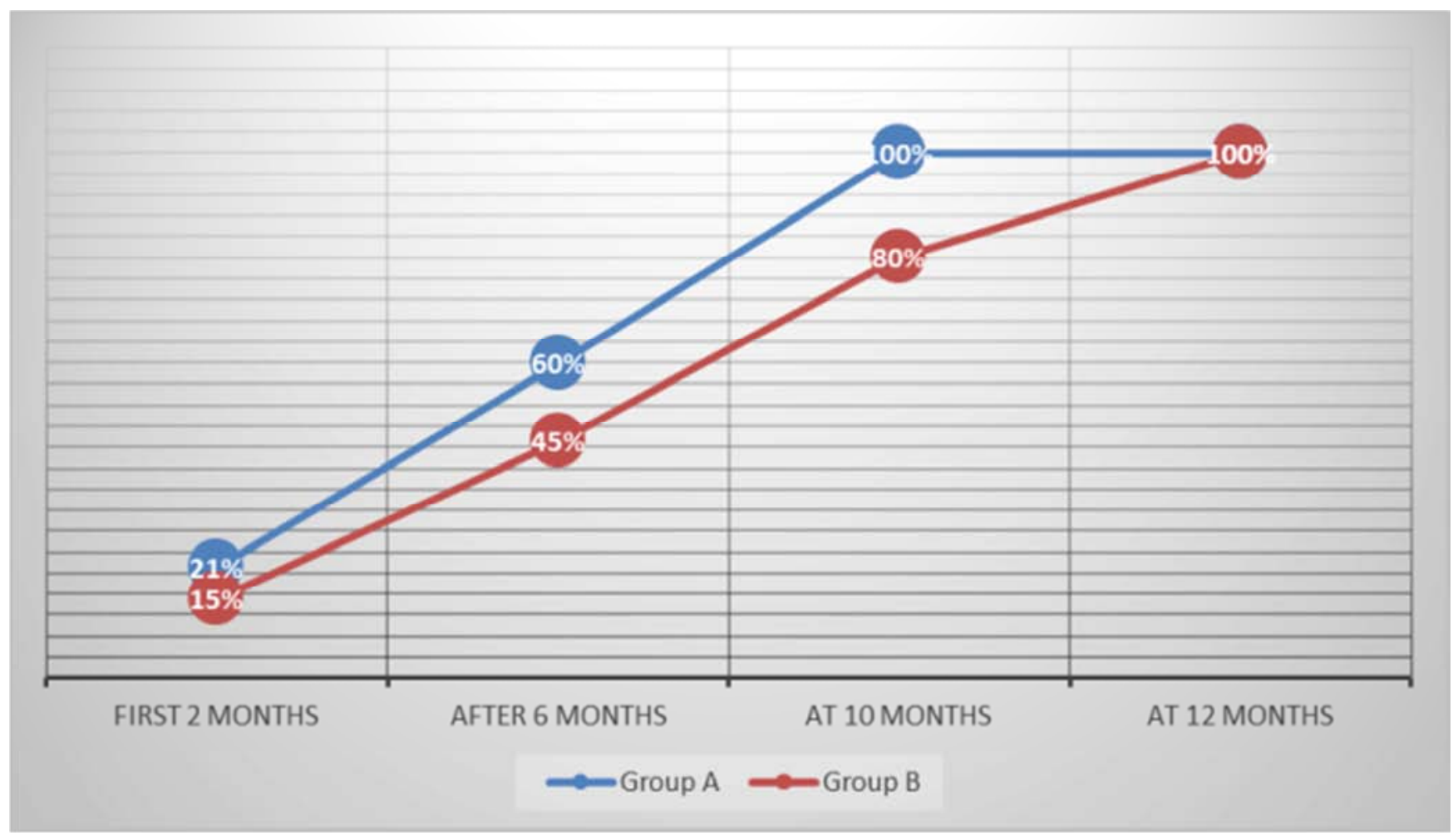

Figure 4. Reduction of the size of Deep and Mixed Hemangioma. 
Table 1. Demographics and disease characteristics.

\begin{tabular}{|c|c|c|c|}
\hline & & Group A & Group B \\
\hline \multirow{3}{*}{ Age of presentation } & Less than 1 month & 98 & 66 \\
\hline & Between 1 month and 1 year & 87 & 72 \\
\hline & More than 1 year & 45 & 82 \\
\hline \multirow{2}{*}{ Gender } & Male & 89 & 73 \\
\hline & Female & 141 & 147 \\
\hline \multirow{3}{*}{ Type of hemangioma } & Superficial & 85 & 30 \\
\hline & Deep & 111 & 158 \\
\hline & Mixed & 36 & 30 \\
\hline \multirow{6}{*}{ Distribution of hemangiomas } & Head and neck & 150 & 120 \\
\hline & Periocular & 6 & 4 \\
\hline & Trunk & 51 & 30 \\
\hline & Extremities & 20 & 21 \\
\hline & Multiple & 14 & 13 \\
\hline & Ulcerated lesions & 34 & 20 \\
\hline
\end{tabular}

Table 2. Indications for treatment (no. of patients).

\begin{tabular}{|c|c|c|c|}
\hline & Combined therapy (230) & Propranolol alone (220) & Total (450) \\
\hline Life-threatening complications & 1 & 1 & 2 \\
\hline Function-threatening complications & 88 & 93 & 181 \\
\hline Permanent aesthetic disfigurement & 102 & 104 & 206 \\
\hline Ulceration & 36 & 18 & 54 \\
\hline Pain & 3 & 4 & 7 \\
\hline
\end{tabular}

Table 3. Distribution of hemangiomas.

\begin{tabular}{|c|c|c|}
\hline Location & & Number of patients and percentage \\
\hline \multirow{7}{*}{ Head and neck } & Total & $270(60 \%)$ \\
\hline & Head & 83 \\
\hline & Cheek & 44 \\
\hline & Nose & 37 \\
\hline & Neck & 38 \\
\hline & Chin and lips & 39 \\
\hline & Periocular & 29 \\
\hline \multirow{3}{*}{ Trunk } & Total & $81(18 \%)$ \\
\hline & Back & 44 \\
\hline & Chest & 37 \\
\hline \multirow{5}{*}{ Extremities } & Total & $72(16 \%)$ \\
\hline & Arm & 22 \\
\hline & Hand & 25 \\
\hline & Leg & 9 \\
\hline & Feet & 16 \\
\hline Multiple lesions & Total & $27(6 \%)$ \\
\hline
\end{tabular}

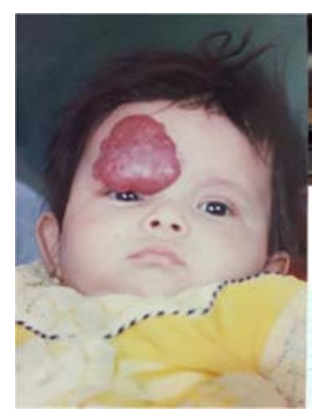

a

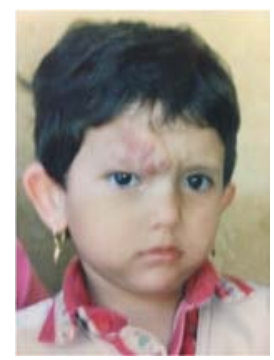

b

Figure 5. A 10-month-old girl with huge periocular infantile hemangioma (a) before initiation of propranolol therapy, (b) 18 months after propranolol monotherapy. 

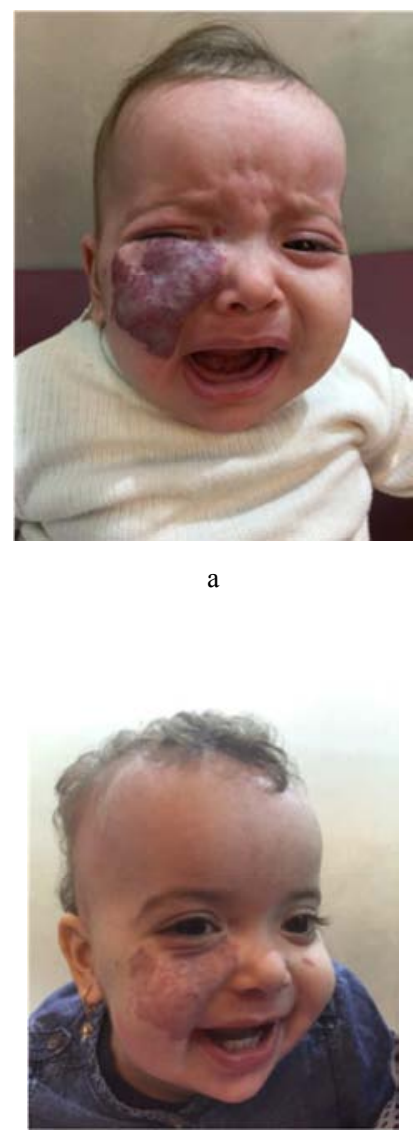

b

Figure 6. A 12-month-old boy with diffuse periocular infantile hemangioma (a) before combined propranolol-steroid therapy, (b) 18 months after combined therapy.
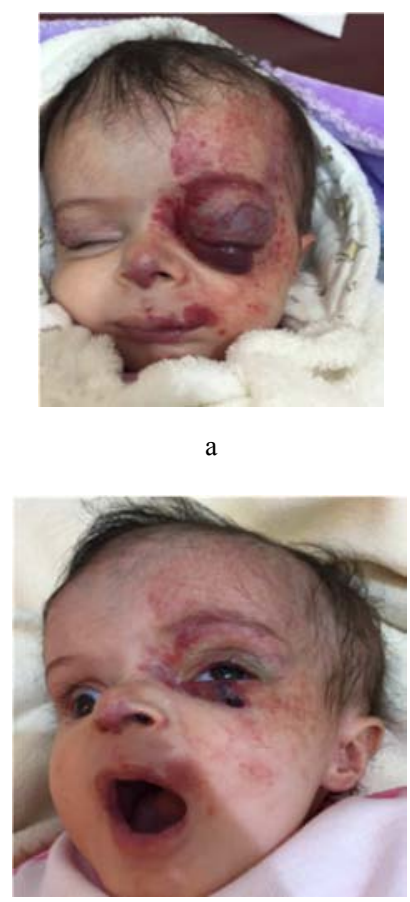

Figure 7. A 6-month-old boy with diffuse periocular Infantile hemangioma (a) before combined propranolol-steroid therapy, (b) 10 months after combined therapy.
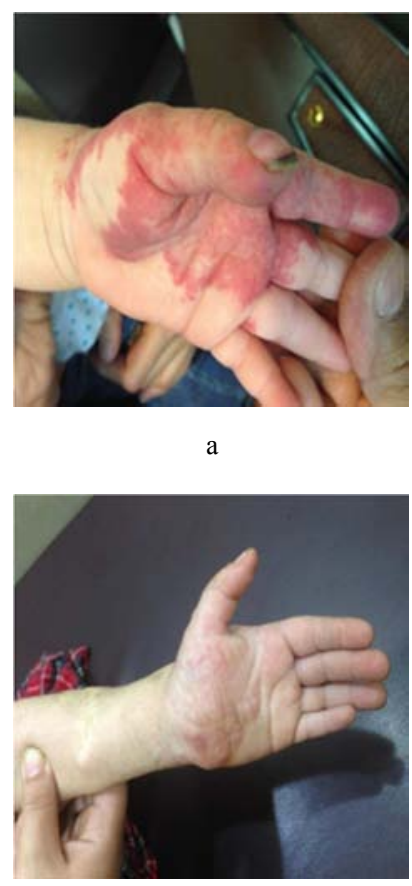

b

Figure 8. A 7 month-boy with diffuse hand infantile hemangioma (a) before initiation of propranolol therapy, (b) 18 months after propranolol monotherapy.

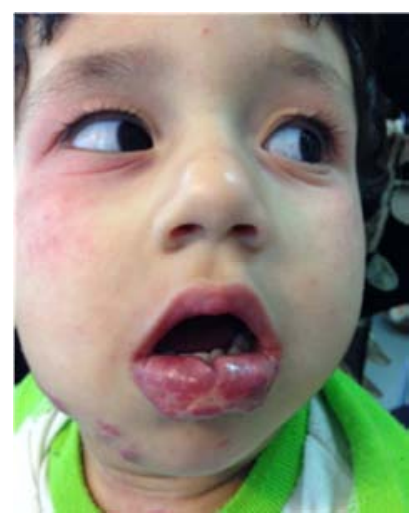

a

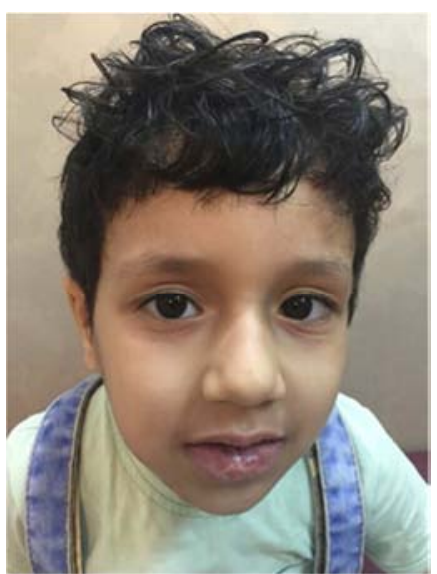

b

Figure 9. A 17-month-old boy with lower lip Infantile hemangioma (a) before combined propranolol-steroid therapy, (b) 18 months after combined therapy. 

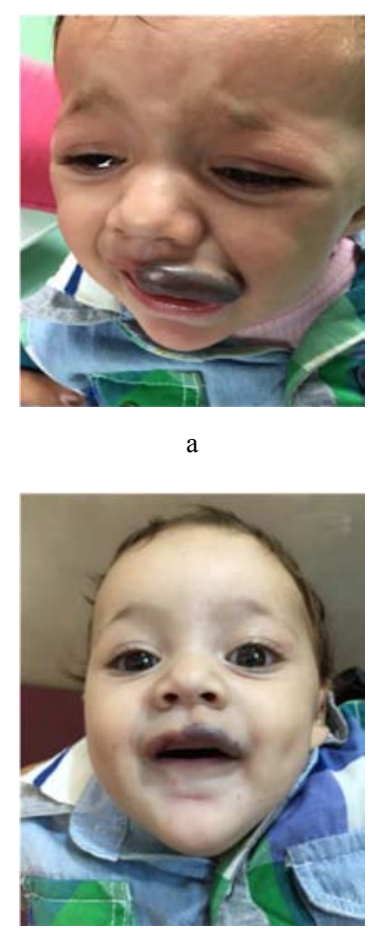

b

Figure10. A 13-month-old boy with upper lip infantile hemangioma (a) before combined propranolol-steroid therapy, (b) 18 months after combined therapy.

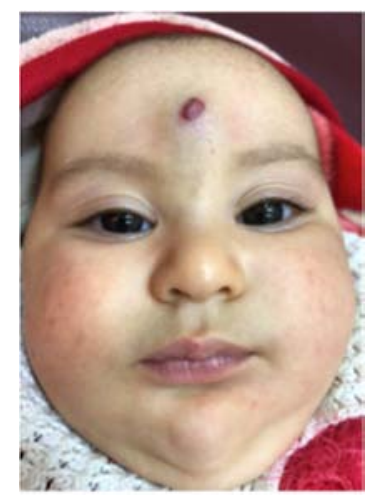

a

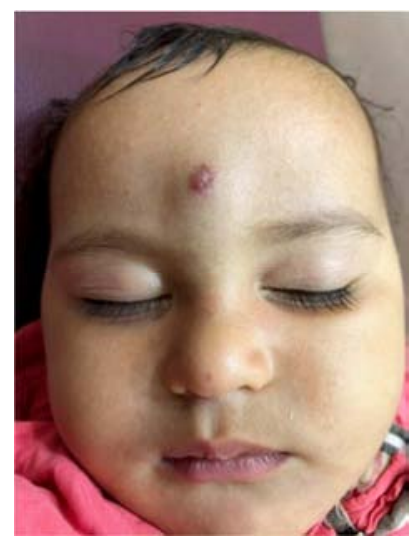

b

Figure 11. A 6-month-old boy with forehead infantile hemangioma (a) before propranolol, (b) 18 months after propranolol monotherapy.

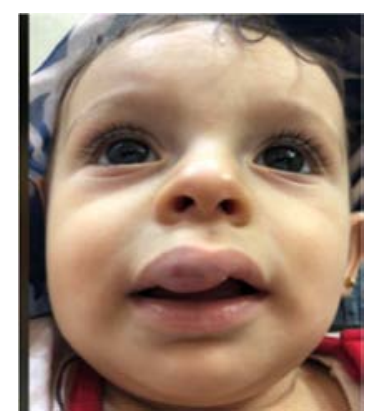

a

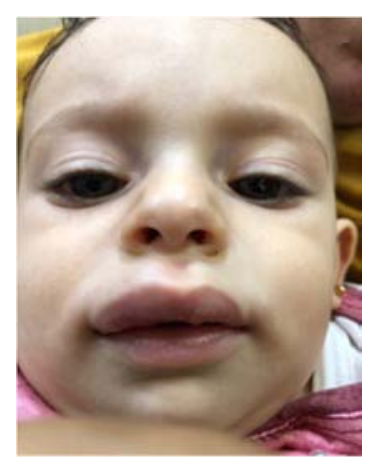

b

Figure 12. A 16-month-old boy with upper lip infantile hemangioma (a) before propranolol, (b) 18 months after propranolol monotherapy.
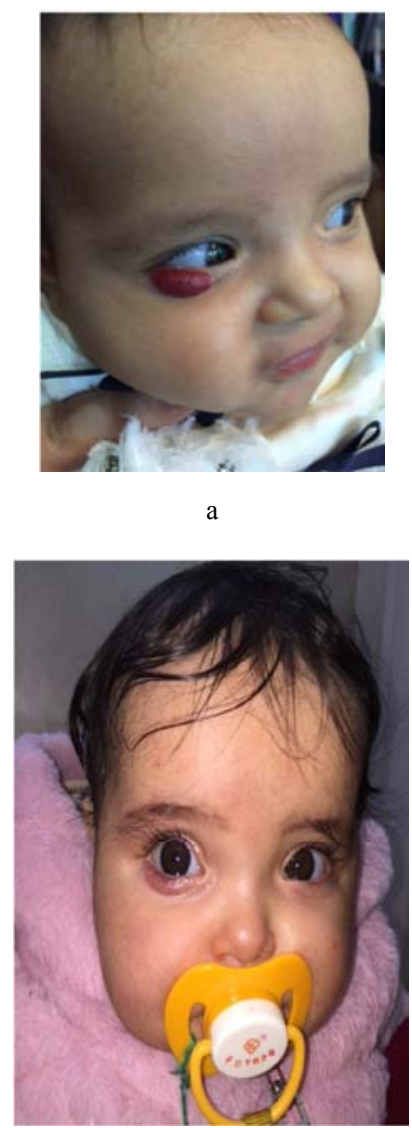

b

Figure 13. A 6-month-old girl with lower lid infantile hemangioma (a) before propranolol, (b) 18 months after propranolol monotherapy. 


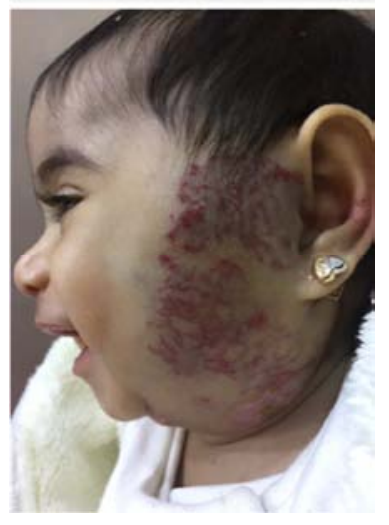

a

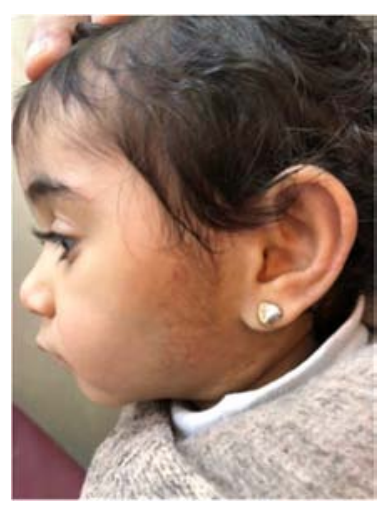

b

Figure 14. A 10-month-old girl with diffuse cheek infantile hemangioma (a) before combined propranolol-steroid therapy (b) 18 months after combined therapy.

\section{Disclosures}

All authors shared in the therapy plan, design and revision of the manuscript.

We have no conflicts of interest to disclose.

This research received no specific grant from any funding agency in the public, commercial or not-for-profit sectors.

Confirmed consent has been obtained from the parents.

Independent Review Board approval from the Faculty of Medicine, Mansoura University, has been obtained.

\section{References}

[1] Hoornweg MJ, Smeulders MJ and Van der Horst CM. Prevalence and characteristics of haemangiomas in young children. Ned. Tijdschr. Geneeskd. 2005; 149 (44): 2455-8.

[2] Dickison P, Christou E and Wargon O. A prospective study of infantile hemangiomas with a focus on incidence and risk factors. Pediatr. Dermatol. 2011; 28 (6): 663-9.

[3] Hoeger PH, Harper JI, Baselga E, Bonnet D, Boon LM, Ciofi Degli Atti M, et al. Treatment of infantile haemangiomas: Recommendations of a European expert group. Eur. J. Pediatr. 2015; 174 (7): 855-65.

[4] Luu M and Frieden IJ. Haemangioma: Clinical course, complications and management. Br. J. Dermatol. 2013; 169 (1):
20-30.

[5] Ranchod TM, Frieden IJ and Fredrick DR. Corticosteroid treatment of periorbital haemangioma of infancy: A review of the evidence. Br. J. Ophthalmol. 2005; 89: 1134-8.

[6] Chamlin SL, Haggstrom AN, Drolet BA, Baselga E, Frieden IJ, Garzon MC, et al. Multicenter prospective study of ulcerated hemangiomas. J. Pediatr. 2007; 151 (6): 684-9.

[7] Izadpanah A, Izadpanah A, Kanevsky J, Belzile E and Schwarz K. Propranolol versus corticosteroids in the treatment of infantile hemangioma: A systematic review and meta-analysis. Plast. Reconstr. Surg. K 2013; 131: 601-13.

[8] Boon LM, MacDonald DM and Mulliken JB. Complications of systemic corticosteroid therapy for problematic hemangioma. Plast. Reconstr. Surg. 2010; 104: 1616-23.

[9] Drolet BA, Frommelt PC, Chamlin SL, Haggstrom A, Bauman $\mathrm{NM}$, Chiu YE, et al. Initiation and use of propranolol for infantile hemangioma: Report of a consensus conference. Pediatrics 2013; 131 (1): 128-40.

[10] El Hachem M, Gesualdo F, Diociaiuti A, Berti I, Vercellino N, Boccaletti V, et al. Safety and effectiveness of oral propranolol for infantile hemangiomas started before 5 weeks and after 5 months of age: An Italian multicenter experience. Ital. J. Pediatr. 2017; 43: 40-46.

[11] Leaute-Labreze C, Hoeger P, Mazereeuw-Hautier J, Guibaud L, Baselga E, Posiunas G, et al. A randomized, controlled trial of oral propranolol in infantile hemangioma. New Engl. J. Med. 2015; 372 (8): 735-46.

[12] Novoa M, Baselga E, Giraldo L, Shahbaz A, Pardo-Hernandez $\mathrm{H}$ and Arevalo-Rodriguez I. Interventions for infantile haemangiomas of the skin: Abridged Cochrane systematic review and GRADE assessments. Br. J. Dermatol. 2019; 180: 527-33.

[13] Berk DR, Berk EJ and Bruckner AL. A novel method for calculating the volume of hemangiomas. Pediatr. Dermatol. 2011; 28 (4): 478-82.

[14] Pandey A, Gangopadhyay AN, Gopal SC, Kumar V, Sharma SP, Gupta DK, et al. Twenty years' experience of steroids in infantile hemangioma: A developing country's perspective. $J$. Pediatr. Surg. 2009; 44: 688-94.

[15] Lèautè-Labrèze C, Dumas de la Roque E, Hubiche T, Boralevi F, Thambo J and Taieb A. Propranolol for severe hemangiomas of infancy. New Engl. J. Med. 2008; 358 (24): 2649-51.

[16] Léauté-Labrèze $\mathrm{C}$, Prey $\mathrm{S}$ and Ezzedine $\mathrm{K}$. Infantile haemangioma: Part I. Pathophysiology, epidemiology, clinical features, life cycle and associated structural abnormalities. $J$. Eur. Acad. Dermatol. Venereol. 2011; 25: 1245-53.

[17] Bingham MM, Saltzman B, Vo NJ and Perkins JA. Propranolol reduces infantile hemangioma volume and vessel density. Otolaryngol. Head Neck Surg. 2012; 147: 338-44.

[18] Greenberger S and Bischoff J. Infantile hemangioma: Mechanism (s) of drug action on a vascular tumor. Cold Spring Harb. Perspect. Med. 2011; 1: a006460.

[19] Egert S, Nguyen N and Schwaiger M. Contribution of alpha adrenergic and beta adrenergic stimulation to ischemia-induced glucose transporter (GLUT) 4 and GLUT1 translocation in the isolated perfused rat heart. Circ. Res. 1999; 84: 1407-15. 
[20] Pope E, Krafchik BR, Macarthur C, et al. Oral versus high-dose pulse corticosteroids for problematic infantile hemangiomas: A randomized, controlled trial. Pediatrics 2007; 119: e12391247.

[21] Rössler J, Schill T, Bähr A, Truckenmüller W, Noellke P and Niemeyer CM. Propranolol for proliferating infantile haemangioma is superior to corticosteroid therapy: A retrospective, single centre study. J. Eur. Acad. Dermatol. Venereol. 2012; 26: 1173-5.

[22] Bertrand J, McCuaig C, Dubois J, Hatami A, Ondrejchak S and Powell J. Propranolol versus prednisone in the treatment of infantile hemangiomas: A retrospective comparative study. Pediatr. Dermatol. 2011; 28: 649-54.

[23] Awadein A and Fakhry MA. Evaluation of intralesional propranolol for periocular capillary hemangioma. Clin. Ophthalmol. 2011; 5: 1135-40.

[24] Schupp CJ, Kleber J-B, Gunther P and Holland-Cunz S. Propranolol therapy in 55 infants with infantile hemangioma: Dosage, duration, adverse effects, and outcome. Pediatr. Dermatol. 2011; 28: 640-44.

[25] Martinez Roca C, Rodríguez Ruíz M, Vilaboa Pedrosa C, Perez Morales ME and Sanchez Palacio JL. Oral propranolol in the treatment of infantile hemangioma: A case series of 50 infants. Eur. J. Pediatr. Dermatol. 2014; 24: 86-90, 2014.

[26] Castaneda S, Garcia E, De la Cruz H, Sanchez-palacio J, Ramirez O and Melendez S. Therapeutic effect of propranolol in Mexican patients with infantile hemangioma. Drugs - Real World Outcomes 2016; 3: 25-31.

[27] Andersen I, Rechnitzer C and Charabi B. Effectiveness of propranolol for treatment of infantile haemangioma. Dan. Med. J. 2014; 61 (2): A4776.

[28] Malik MA, Menon P, Rao KL and Samujh R. Effect of propranolol vs. prednisolone vs. propranolol with prednisolone in the management of infantile hemangioma: A randomized controlled study. J. Pediatr. Surg. 2013; 48 (12): 2453-9.

[29] Ma X, Zhao T, Xiao Y, Yu J, Chen H, Huang Y, et al. Preliminary experience on treatment of infantile hemangioma with low-dose propranolol in China. Eur. J. Pediatr. 2013; 172 (5): 653-9.

[30] Koay AC, Choo MM, Nathan AM, Omar A and Lim CT. Combined low-dose oral propranolol and oral prednisolone as first-line treatment in periocular infantile hemangiomas. $J$. Ocul. Pharmacol. Ther. 2011; 27: 309-11.

[31] Rosbe KW, Suh KY, Meyer AK, Maguiness SM and Frieden IJ. Propranolol in the management of airway infantile hemangiomas. Arch. Otolaryngol. Head Neck Surg. 2010; 136: 65865.

[32] Hogeling M, Adams S and Wargon O. A randomized controlled trial of propranolol for infantile hemangiomas. Pediatrics 2011; 128: e259-66.

[33] Holland KE, Frieden IJ, Frommelt PC, Mancini AJ, Wyatt D and Drolet BA. Hypoglycemia in children taking propranolol for the treatment of infantile hemangioma. Arch. Dermatol. 2010; 146: 775-8.

[34] Morrell DS, Buck S, Zdanski C, Gold S, Stavas J, Blatt J et al. Beta-blockers for infantile hemangiomas: A single institution experience. Clin. Pediatr. (Phila.) 2011; 50: 757-63.

[35] Fulkerson DH, Agim NG, Al-Shamy G, Metry DW, Izaddoost SA and Jea A. Emergent medical and surgical management of mediastinal infantile hemangioma with symptomatic spinal cord compression: Case report and literature review. Child. Nerv. Syst. 2010; 26: 1799-805.

[36] Bagazgoitia L, Hernandez-Martin A and Torrelo A. Recurrence of infantile hemangiomas treated with propranolol. Pediatr. Dermatol. 2011; 28 (6): 658-62.

[37] Tan ST, Itinteang T and Leadbitter P. Low-dose propranolol for infantile hemangioma. J. Plast. Reconstr. Aesthet. Surg. 2011; 64 (3): 292-9.

[38] Rubin L, Levin M, Ljungman P, Davies E, Avery R, Tomblyn $\mathrm{M}$, et al. 2013 IDSA clinical practice guideline for vaccination of the immunocompromised host. Clin. Infect. Dis. 2014; 58 (3): e44-100. 